\title{
CHARACTERISTICS AND OUTCOME OF ACUTE CLOZAPINE INTOXICATED PATIENTS WITH SPECIAL CONCIDERATION TO ITS CARDIAC MANIFESTATIONS
}

\author{
Wesam Abdalsalam Abdalwahab *and Hanan Mohamed A. Elwahab** \\ * Al-Azhar University, Faculty of Medicine for girls - Forensic Medicine and Clinical \\ Toxicology Department \\ ** Poison Control Center-Ain Shams University Hospitals \\ The corresponding author: Wesam Abdalsalam Abdalwahab \\ Email: w_abdalwahab@yahoo.com
}

\begin{abstract}
Background: Clozapine is a typical antipsychotic drug that has been used for the management of treatment-resistant schizophrenia. Its toxicity may cause serious manifestations as cardiomyopathy and myocarditis which may be fatal. Aim: This study focused on determination of the features of acute clozapine intoxication with special consideration to its cardiac manifestations. Patients and Methods: This study was a cross-sectional study of six months duration to selected cases with isolated clozapine toxicity who had been admitted to the poison control center of Ain Shams University Hospitals(PCC-ASUH ) during the period from the first of March 2019 to the end of August 2019 who fulfilled the inclusion and exclusion criteria. The collected data included sociodemographic, intoxication, clinical data and outcome of patients. Cardiac manifestations were also recorded. Routine investigations were done for each patient including ECG recordings. Results: This study was conducted on 107 cases; most of them were males $(55.14 \%)$ with the mean age of $17.22 \pm 12.52$ years. Most of clozapine toxicity was suicidal. Clozapine was taken through ingestion with mean dose of $7.88 \pm 5.26$ tablets. The mean delayed time was $6.15 \pm 6.35$ hours. $84.1 \%$ of the cases were admitted to ICU, only one case needed mechanical ventilation. All cases discharged with no deaths. Most of the cases were comatose. Regarding cardiac manifestations most cases were tachycardic, hypotensive, tachypneic and had abnormal ECG findings. Conclusion: Acute clozapine intoxication is not a rare presentation to the poison control center but not fatal. Most cases presented with coma. Its cardiac manifestations included tachycardia, hypotension, tachypnea and abnormal ECG findings.
\end{abstract}

KEYWORDS: clozapine, acute toxicity, outcome, cardiac manifestations

\section{INTRODUCTION}

Clozapine is a typical antipsychotic drug that was first made in 1956 based on chemical structure of tricyclic antidepressant imipramine was sold in 1972(Goto et al., 2017). It is prescribed in treating refractory schizophrenia but its use is limited because of its lethal effects (Warnez and Alessi-Severini, 2014).

Clozapine antagonizes 5HT2A subunit of serotonin and binds to dopamine receptors so improves depression and anxiety (Robinson., 
2007). It also has direct interaction with gamma-aminobutyric acid (GABAB) receptor (Wu et al., 2011).

Absorption of clozapine is complete after oral administration, then in the liver it is metabolized

to polar metabolites by cytochrome P450 system to be excreted in urine and feces. Norclozapine is its major pharmacologically active metabolite (Johal and Barrera.,2019).

Many factors predispose to clozapine toxicity as genetic polymorphisms of cytochrome oxidase enzymes, inflammation, intervening physical illness, concurrent drug use and old age (Kamış et al.,2014).

Manifestations of clozapine toxicity include tachycardia, respiratory depression, confusion, agitation, drowsiness, hypotension, lethargy and seizures (Macfarlane et al., 2020).

Clozapine may suppressed immunity and its toxicity may cause inflammation of the heart which is fatal (Hartling et al., 2012) and in a systematic review by Bellissima et al., (2018) they found a total of 3347 articles addressed cardiac complications of clozapine; 82 articles of them were about cases of clozapine-induced myocarditis.

AS there are few researches describing acute clozapine intoxication (Lebin et al.,2018); this study focused on determination of the features of acute clozapine intoxication with special consideration to its cardiac manifestations as early diagnosis and appropriate treatment is often lifesaving

\section{SUBJECTS \& METHODS}

Type of the study: A crosssectional study.

Inclusion criteria: This study included patients of both sexes with isolated acute clozapine toxicity who were admitted to the Poison Control Center of Ain Shams University Hospitals (PCC-ASUH) during a period of six months from the first of March 2019 to the end of August 2019.

Exclusion criteria: Poisoned patients with other types of poisoning rather than clozapine, patients with co administration of drugs or poisons and patients with history of chronic cardiac, respiratory, hepatic or renal diseases were excluded from the study.

Ethical considerations: The study was approved by the Research Ethics Committee of Faculty of medicine for girls Al-Azhar University with a code number (202003177) and a full informed consent was obtained from patients or their guardians.

Data collection: A special observation sheet was designed included demographic data (age, sex), intoxication data (clozapine dose, route of exposure, delay time, mode of poisoning, symptoms), in addition to cardiac manifestations (pulse, blood pressure, respiratory rate and ECG records). Normal values were stated according to McGrath and Bachmann (2018). Outcome of patients, need for mechanical ventilation, and ICU admission and its duration of stay were also recorded. 
Clinical examinations were performed for each patient on admission. All patients received therapeutic interventions including gut decontamination, charcoal administration and standard supportive care when indicated following the guidelines of the PCC-ASUH protocols. Patients who presented with severe manifestations like respiratory distress, arrhythmia, shock, coma or convulsions were admitted to ICU.

Sampling: Two venous blood samples were collected on admission for each patient before receiving any treatment. One was anticoagulated with EDTA to measure total leukocytic count (TLC). The other sample was transferred to a clean dry centrifuge tube and left for few hours to clot. After complete clotting, it was centrifuged for 10 minutes at $5000 \mathrm{rpm}$. Serum was separated, stored in the freezer and used later after collection of all samples for measurement of serum glucose, AST, ALT and BUN.

ECG analysis: It included rate, rhythm, ST/T abnormalities and measurement of Q-T intervals. The QT interval was corrected (QTc) according to the formula of Bazett, in which the QT interval is adjusted for heart rate by dividing it by the square root of the R-R interval. $\mathrm{QT} c=\mathrm{QT} / \sqrt{ } \mathrm{RR}$ (Postema and Wilde ,2014).

\section{Statistical analysis:}

Recorded data were analyzed using the statistical package for social sciences, version 20.0 (SPSS Inc., Chicago, Illinois, USA). Quantitative data were expressed as mean \pm standard deviation (SD). Qualitative data were expressed as frequency and percentage. Independent-samples t-test of significance was used when comparing between two means. Mann Whitney ztest: for two-group comparisons in nonparametric data. Chi-square (x2) test of significance was used in order to compare proportions between qualitative parameters. The confidence interval was set to $95 \%$ and the margin of error accepted was set to $5 \%$. $p$ value level of significance; $p>0.05$ : Nonsignificant. $\mathrm{p} \leq$ 0.05: Significant. $\mathrm{p} \leq 0.001$ : Highly significant.

\section{RESULTS}

This study was conducted on 107 cases with acute clozapine toxicity were admitted to the PCC-ASUH during the study period and fulfilled inclusion and exclusion criteria.

Most of studied patients were males $59(55.14 \%)$ with the mean age of $17.22 \pm 12.52$ years. According to the mode of poisoning, it was suicidal and accidental in $54.21 \%$ and $45.79 \%$ of the cases respectively. All patients had taken clozapine through ingestion with mean dose of $7.88 \pm 5.26$ tablets. The mean delayed time was $6.15 \pm 6.35$ hours. $84.1 \%$ of the cases were admitted to ICU with $2.43 \pm 1.00$ days as mean duration of stay and only one case needed mechanical ventilation. As regards the fate all studied cases discharged with no deaths (Table 1).

Table (2) shows the characteristic clinical presentations of studied patients. Coma is the most common 
presenting sign of the clozapine poisoned cases $(84.1 \%), 70.1 \%$ of them were in Grade I and $14.0 \%$ were in Grade II. Other symptoms were extra pyramidal manifestations in $15.9 \%$, drowsiness in $8.4 \%$, agitation in $6.5 \%$, hallucinations or vomiting in $5.6 \%$, constricted pupil in $4.7 \%$, seizures, numbness or shock in $0.9 \%$.

Table (3) shows investigations of clozapine intoxicated patients; clozapine was of high significant effect $(p<0.001)$ on serum glucose and total leucocytic count as confirmed by Z-test. All cases had high total leucocytic count (TLC), most of them were hyperglycemic $(79.4 \%)$. Also, clozapine significantly $(\mathrm{p}<0.05)$ affects AST and BUN. According to cardiac manifestations of the studied cases, clozapine was of high significant effect $(p<0.001)$ on pulse and blood pressure as confirmed by Z-test. Most of the cases were tachycardic $(77.7 \%)$ and hypotensive $(60.75 \%)$. Clozapine also significantly ( $\mathrm{p}<0.05)$ affects the

Table (1): Descriptive parameters of the clozapine intoxicated patients

\begin{tabular}{|c|c|}
\hline Parameters & Total $(n=107)$ \\
\hline \multicolumn{2}{|l|}{ Sex } \\
\hline Male n(\%) & $59(55.14 \%)$ \\
\hline Female n(\%) & $48(44.86 \%)$ \\
\hline Age (years) Range (Mean $\pm S D)$ & $0.5-62[17.22 \pm 12.52]$ \\
\hline Amount (tablets) Range (Mean $\pm S D)$ & $1-30[7.88 \pm 5.26]$ \\
\hline Route & Oral route \\
\hline \multicolumn{2}{|l|}{ Mode of poisoning: } \\
\hline Accidental n (\%) & $49(45.79 \%)$ \\
\hline Suicidal n (\%) & $58(54.21 \%)$ \\
\hline Delayed time (hours) Range (Mean $\pm S D$ ) & $1-29[6.15 \pm 6.35]$ \\
\hline Admission on ICU n (\%) & $90(84.1 \%)$ \\
\hline $\begin{array}{l}\text { Duration of stay in the ICU (days) } \\
\text { Range (Mean } \pm S D)\end{array}$ & $1-7[2.43 \pm 1.00]$ \\
\hline Mechanical ventilation $n(\%)$ & $1(0.9 \%)$ \\
\hline Fate (survival) n (\%) & $107(100 \%)$ \\
\hline
\end{tabular}

respiratory rate and ECG findings as confirmed by Z-test. More than half of patients were tachypneic $(60.75 \%)$ and had abnormal ECG findings (63.60\%) (Table 4).

Regarding ECG abnormalities among studied patients, clozapine had significant effect on the heart rate and $\mathrm{T}$ wave. The most common ECG abnormality was sinus tachycardia in $63.60 \%$ followed by supra ventricular tachycardia in 15. 9\%. Abnormal $\mathrm{T}$ wave and ST segment was found in $9.35 \%$ and $6.50 \%$ respectively. Other abnormalities were in the form of premature ventricular contraction in6.5\% and prolonged QTc interval in $4.70 \%$ of the cases (Table 5).

$n:$ number 
Table (2): Characteristic clinical presentations of the clozapine intoxicated patients on admission

\begin{tabular}{|l|c|}
\hline Parameters & $\begin{array}{c}\text { Total }(\mathbf{n = 1 0 7}) \\
\mathbf{n}(\mathbf{\%})\end{array}$ \\
\hline Extra pyramidal manifestations & $17(15.9 \%)$ \\
\hline Drowsy & $9(8.4 \%)$ \\
\hline Agitation & $7(6.5 \%)$ \\
\hline Hallucinations & $6(5.6 \%)$ \\
\hline Vomiting & $6(5.6 \%)$ \\
\hline Constricted pupil & $5(4.7 \%)$ \\
\hline Seizures & $1(0.9 \%)$ \\
\hline Numbness & $1(0.9 \%)$ \\
\hline Shock & $1(0.9 \%)$ \\
\hline Coma & $90(84.1 \%)$ \\
\hline Grade I & $75(70.1 \%)$ \\
\hline Grade II & $15(14.0 \%)$ \\
\hline
\end{tabular}

$n$ :

number

Table (3): Investigations of clozapine intoxicated patients on admission

\begin{tabular}{|c|c|c|c|}
\hline Parameters & Total $(n=107)$ & z-test & p-value \\
\hline \multicolumn{4}{|l|}{ Serum Glucose $(\mathrm{mg} / \mathrm{dl})$} \\
\hline Normal n (\%) & $31(17.7 \%)$ & \multirow{4}{*}{173.120} & \multirow{4}{*}{$<0.001 * *$} \\
\hline Hyperglycemia $>110$ n (\%) & $139(79.4 \%)$ & & \\
\hline Hypoglycemia<70 n (\%) & $5(2.9 \%)$ & & \\
\hline Range (Mean $\pm S D)$ & $40-436[126.92 \pm 65.71]$ & & \\
\hline \multicolumn{4}{|l|}{ TLC } \\
\hline Normal n (\%) & $0(00 \%)$ & \multirow{3}{*}{83.358} & \multirow{3}{*}{$<0.001 * *$} \\
\hline Leukocytosis n (\%) & $107(100 \%)$ & & \\
\hline Range [Mean \pm SD] & $4.9-18.3[9.31 \pm 3.41]$ & & \\
\hline \multicolumn{4}{|l|}{ AST } \\
\hline Normal n (\%) & $156(89.1 \%)$ & \multirow{3}{*}{17.251} & \multirow{3}{*}{$0.021 *$} \\
\hline Elevated $>37 U / L \mathbf{n}(\%)$ & $19(10.9 \%)$ & & \\
\hline Range [Mean \pm SD] & $9-51[22.59 \pm 12.63]$ & & \\
\hline \multicolumn{4}{|l|}{ ALT } \\
\hline Normal n (\%) & $107(100 \%)$ & \multirow{2}{*}{0.000} & \multirow{2}{*}{1.000} \\
\hline Range [Mean \pm SD] & $5-32[11.89 \pm 7.97]$ & & \\
\hline \multicolumn{4}{|l|}{ BUN } \\
\hline Normal n (\%) & $152(86.9 \%)$ & \multirow{3}{*}{19.091} & \multirow{3}{*}{$0.011 *$} \\
\hline Elevated $>25 \mathrm{mg} / \mathrm{dL} \mathbf{n}(\boldsymbol{\%})$ & $23(13.1 \%)$ & & \\
\hline Range [Mean \pm SD] & $5-39.7[17.52 \pm 6.99]$ & & \\
\hline
\end{tabular}

N: number; TLC: total leucocytic count; AST: aspartate aminotransferase; ALT:

alanine aminotransferase; BUN: blood urea nitrogen; SD: standard deviation; $p$-value $>0.05$ Non significant; *p-value <0.05 Significant; $* *$-value $<0.001$ highly significant 
Table 4: Cardiac manifestations of acute clozapine intoxicated patients

\begin{tabular}{|c|c|c|c|}
\hline Parameters & Total $(n=107)$ & z-test & p-value \\
\hline Pulse & & & \\
\hline Normal n (\%) & $31(17.7 \%)$ & \multirow{4}{*}{159.646} & \multirow{4}{*}{$<0.001 * *$} \\
\hline Tachycardia >90 n (\%) & $136(77.7 \%)$ & & \\
\hline Bradycardia $<60$ n (\%) & $8(4.6 \%)$ & & \\
\hline Range $($ Mean $\pm S D)$ & $70-190[118.91 \pm 24.80]$ & & \\
\hline \multicolumn{4}{|l|}{ Blood pressure } \\
\hline Normal n (\%) & $35(32.71 \%)$ & \multirow{3}{*}{47.178} & \multirow{3}{*}{$<0.001 * *$} \\
\hline Hypertension $\mathbf{n}(\%)$ & $7(6.54 \%)$ & & \\
\hline Hypotension $\mathbf{n}(\boldsymbol{\%})$ & $65(60.75 \%)$ & & \\
\hline \multicolumn{4}{|l|}{ Respiratory rate } \\
\hline Normal n (\%) & $42(39.25 \%)$ & \multirow{3}{*}{4.944} & \multirow{3}{*}{$0.026^{*}$} \\
\hline Tachypnea n (\%) & $65(60.75 \%)$ & & \\
\hline Range (Mean $\pm S D)$ & $10-30$ & & \\
\hline \multicolumn{4}{|l|}{ ECG comment } \\
\hline Normal n (\%) & $39(36.40 \%)$ & \multirow{2}{*}{17.860} & \multirow{2}{*}{$0.005^{*}$} \\
\hline Abnormal n (\%) & $68(63.60 \%)$ & & \\
\hline
\end{tabular}

$n$ : number SD: standard deviation, p-value >0.05 NS; *p-value <0.05 S; **p-value $<0.001$

Table (5): Electrocardiographic (ECG) abnormalities of acute clozapine intoxicated patients

\begin{tabular}{|c|c|c|c|}
\hline Parameters & Number (\%) & z-test & p-value \\
\hline Rate \& Rhythm & & \multirow{5}{*}{120.462} & \multirow{5}{*}{$<0.001 * *$} \\
\hline Sinus tachycardia & $68(63.60 \%)$ & & \\
\hline Supra Ventricular Tachycardia & $17(15.9 \%)$ & & \\
\hline Premature ventricular contraction & $7(6.5 \%)$ & & \\
\hline$A F$ & $1(0.9 \%)$ & & \\
\hline \multicolumn{4}{|l|}{ QTc interval } \\
\hline Normal & $102(95.30 \%)$ & \multirow{2}{*}{3.935} & \multirow{2}{*}{0.091} \\
\hline Prolonged & $5(4.70 \%)$ & & \\
\hline \multicolumn{4}{|l|}{ ST segment } \\
\hline Normal & $100(93.50 \%)$ & \multirow{2}{*}{3.832} & \multirow{2}{*}{0.104} \\
\hline Abnormal & $7(6.50 \%)$ & & \\
\hline \multicolumn{4}{|l|}{ T wave } \\
\hline Normal & $97(90.65 \%)$ & \multirow{2}{*}{9.738} & \multirow{2}{*}{$0.031^{*}$} \\
\hline Abnormal & $10(9.35 \%)$ & & \\
\hline
\end{tabular}

P-value >0.05 Non significant; *p-value <0.05 Significant; **p-value <0.001 highly significant

\section{DISCUSSION}

Clozapine is a typical antipsychotic drug antagonizing dopamine (D1 and D2), muscarinic and alpha1- adrenoceptor receptors (Macfarlane et al., 2020). It is effective in treating refractory schizophrenia (Taylor et al., 2017). 
Clozapine causes serious manifestations as myocarditis, cardiomyopathy and agranulocytosis (Alawami et al., 2014).

Myocarditis is one of the most publicized cardiotoxic side effects of clozapine. Also, dilated cardiomyopathy and pericarditis have been reported (Abbas and Abbas.,2016).

So, this study focused on determination of the features of acute clozapine intoxication with special consideration to its cardiac manifestations as early identification of the signs and symptoms of clozapine intoxication and its effective management are of great importance.

This study was conducted on 107 cases with acute clozapine toxicity were admitted to the PCC-ASUH during the study period and fulfilled inclusion and exclusion criteria.

Most of studied patients were males with the mean age of $17.22 \pm 12.52$ years. Most of clozapine toxicity was suicidal. All patients had taken clozapine through ingestion with mean dose of $7.88 \pm 5.26$ tablets. The mean delayed time was $6.15 \pm 6.35$ hours. Most of the cases were admitted to ICU with mean duration of stay $2.43 \pm 1.00$ days and only one case needed mechanical ventilation. As regards the fate all studied cases discharged with no deaths.

These results were somehow in accordance with He et al., (2007) as they found that the mean age of their patients was $39.0 \pm 12.2$ years, the mean delayed time was 6.5 hours and only one patient died from pulmonary edema and subsequent heart failure.
Koller et al.,(2001) found the mean age of their patients was $40 \pm 12$ years and the male to female ratio was 2:0.

In the current study coma was the commonest presenting sign of clozapine poisoned cases. This was in agreement with Lebin et al., (2018) who stated that coma is the most observed symptom in clozapine toxicity and could be due to its antagonistic effect to histamine $\mathrm{H} 1$ receptor.

Also, He et al., (2007) found coma in $44.68 \%$ of their patients. While Bellissima et al., (2018) found shortness of breath, fever and tachycardia were the most common clinical presentations of clozapine toxicity.

Other signs of the patients in the present study were extra pyramidal manifestations, drowsiness, agitation, hallucinations, vomiting, constricted pupil, seizures, numbness and shock.

These were coincided with what is mentioned by Greenwood-Smith et al., (2003) that the symptoms of clozapine toxicity, include confusion, tachycardia, miosis and leukocytosis which were all observed in our patients.

Also, Kamış et al., (2014) reported that pupils of their case were bilaterally miotic.

Warnez and Alessi-Severini (2014) mentioned clozapine adverse effects which include tachycardia, hyperglycemia, weight gain, seizures, myocarditis and neuromalignant syndrome.

The occurrence of seizures is supported and explained by Lebin et al., (2018) who reported that clozapine lowers the seizure threshold through 
antagonizing gamma-aminobutyric acid receptor.

Johal and Barrera., (2019) reported that clozapine is associated with a risk of diabetes and this was coincided with the results of the present study as most of the cases were hyperglycemic.

Koller et al.,(2001) identified 384 reports of hyperglycemia in clozapine intoxicated patients.

Clozapine may cause hyperglycemia either by increasing insulin resistance, reducing insulin secretion or by alteration of a regulatory molecule as glucagon (Chathoth et al., 2018).

In the current study, all clozapine intoxicated patients had high total leucocytic count and this was in agreement with Gerasimou et al.,(2017) as they found blood tests of their cases were within normal except for leukocytosis.

Kamış et al., (2014) stated that one of the lethal effects of clozapine is neuroleptic malignant syndrome (NMS) which is characterized by leukocytosis, fever, autonomic dysfunction, altered mental status and rigidity.

While Numata et al., (2018) found that one year of administration of clozapine resulted in agranulocytosis in $0.8 \%$ of the patients.

Midbari et al., (2013) reported that clozapine-induced agranulocytosis can be transient.

The mechanisms by which clozapine induced leukocytosis may be related to changes in plasma concentrations of granulocyte colonystimulating factor, interleukin (IL)-2 and IL-6 cytokines and tumor necrosis factor- $\alpha$ (Song et al., 2018).

Some clozapine intoxicated patients in the current study had elevated AST and BUN levels.

These results could be explained by Gerasimou et al.,(2017)who found an ongoing inflammatory process under clozapine titration.

This was in accordance with Kramer et al., (2010) who stated that hepatitis may be an evidence of clozapine toxicity. And was supported by Chan et al., (2015) and DeLucia, (2019) who identified 13case reports with acute interstitial nephritis due to clozapine toxicity.

Kamış et al., (2014) found increased level of BUN while liver function tests were within normal range.

Johal and Barrera., (2019) reported that mortality in clozapine toxicity may be due to sudden severe cardiac complications as pericarditis, myocarditis and cardiomyopathy.

As regards cardiac manifestations most cases of the present study were tachycardic $(77.7 \%)$, hypotensive $(60.75 \%)$, tachypneic $(60.75 \%)$ and had abnormal ECG findings (63.60\%).

These findings were in agreement with He et al., (2007) as they found tachycardia and hypotension in $68.5 \%$ and $25.5 \%$ of their patients respectively and $17.02 \%$ of their patients had abnormal ECG findings.

These findings were supported by Kramer et al., (2010) who stated that abnormalities of blood pressure are evidences of clozapine toxicity.

Tachycardia could be due to clozapine's partial antagonism to 
muscarinic receptor that resulted in anticholinergic toxidrome (Lebin et al.,2018).

As clozapine blocks alpha adrenergic receptors hypotension may be present and even vasopressors may be needed (West et al.,2013).

In the present study, the commonest ECG abnormality was sinus tachycardia followed by supra ventricular tachycardia. Abnormal $\mathrm{T}$ wave, ST segment, premature ventricular contraction and prolonged QTc were also found.

These were in agreement with Gerasimou et al.,(2017) who reported that all ECG of their cases revealed sinus tachycardia.

In a study by Kamış et al., (2014) they found that clozapine toxicity resulted in ventricular extrasystoles.

Gerasimou et al., (2017) explained cardiotoxicity of clozapine by many mechanisms, it either affects the heart directly or indirectly by alterations of hemodynamic flow, formation of free radicals, cell apoptosis or enhancing the immunological reactions.

Abdel-Wahab and Metwally, (2015) reported that clozapine may induce myocarditis through immunological-mediated mechanisms by stimulating pro-inflammatory cytokines production as TNF $\alpha$, IL1 and IL6 causing myocardial depression by direct actions on the myocytes Gerasimou et al., (2017).

\section{CONCLUSIONS}

Acute clozapine intoxication is a frequent presentation to the Poison Control Center of Ain Shams University Hospitals (PCC-ASUH) but not fatal. Most cases presented with coma. Its cardiac manifestations included tachycardia, hypotension, tachypnea and abnormal ECG findings.

\section{REFERENCES}

Abbas, M. F. and Abbas, A. H. (2016): Clozapine-induced myocarditis in rats: role of LCarnitine in protection. Egypt J. Forensic Sci. Appli. Toxicol.; 16 (1) :141-157.

Abdel-Wahab, B.A. and Metwally, M.E. (2015): Clozapine-induced cardiotoxicity. Role of oxidative stress, tumor necrosis factor alpha and NF- $\mathrm{k} \beta$. Cardiovasc Toxicology;15(4)

:355-365

Alawami, M.; Wasywich, C.; Cicovic, A. and Kenedi, C. (2014): A systematic review of clozapine induced cardiomyopathy. Int. J. Cardiol. 176, 315-320.

Bellissima, B.L.; Tingle, M..D.; Cicović, A.; Alawami, M .and Kenedi, C. (2018): A systematic review of clozapineinduced myocarditis. Int J Cardiol.; 15;259:122-129. doi: 10.1016/j.ijcard.2017.12.102.

Chan, S.Y.; Cheung, C.Y. and Chan, P.T. (2015): Clozapine-induced acute interstitial nephritis. Hong Kong Med J.;21:372-374.

Chathoth, V. ; Ramamurthy, P. and Solomon, S. (2018):Clozapineinduced Insulin-resistant Hyperglycemia in a Diabetic Patient. Indian J Psychol Med.; 40(4): 375-377. 
DeLucia, B. (2019): Clozapineassociated kidney injury complicated by lithium toxicity a case report and literature review. Journal of Clinical Psycho pharmacology; 39(3).

Gerasimou, C. ; Vitali, G. P. and George, D. (2017): Clozapine Associated with Autoimmune Reaction, Fever and Low-Level Cardiotoxicity - A Case Report. In Vivo.; 31(1): 141-144.

Goto, A.; Yoshimi, A.; Nagai, T.; Ukigai, M.; Mouri, A. and Ozaki, N. (2017):Human neutrophils show decreased survival upon long-term exposure to clozapine. Hum Psycho pharmacology. ;32(6).

Greenwood-Smith, C.L.; Ubman, D.I. and Castle, D.J. (2003): Serum clozapine levels: a review of their clinical utility J Psychopharmacol; 17: 234-238.

Hartling, L.; Abou-Setta, A.M.; Dursun, S.; Mousavi, S.S.; Pasichnyk, D. and Newton, A.S. (2012): "Antipsychotics in adults with schizophrenia: comparative effectiveness of first-generation versus second-generation medications: a systematic review and meta-analysis". Annals of Internal Medicine. 157 (7): 498511.

He, J.L.; Xiang, Y.T.; Li, W.B.; Cai, Z.J. and Ungvari, G.S.(2007): Hemoperfusion in the treatment of acute clozapine intoxication in
China. J Clin

Psychopharmacol.;27(6):667-71.

Johal, H.K. and Barrera, A. (2019): Clozapine-induced pericarditis: an ethical dilemma. BMJ Case Rep;12: e229872.

Kamış, G.Z.; Ayhan, Y. ; Basar, K. and Suzan Özer, A. (2014): A case of clozapine intoxication presenting with atypical NMS symptoms. International Journal of Neuropsychopharmacology; 17(5):819-821.

Koller, E.; Schneider, B.; Bennett, K. and Dubitsky, G. (2001): Clozapine-associated diabetes. Am J Med.; 111:716-23

Kramer, I.; RauberLuthy,C.;Kupferschmidt, H.; Krahenbuhl ,S., and Ceschi, A. (2010): Minimal dose for severe poisoning and influencing factors in acute human clozapine intoxication: a 13-year retrospective study Clinical Neuropharm33:230-234

Lebin, J. A. ; Villarreal, J. D. ; Chen, B. C. and Hall, M. K. (2018):Clozapine Intoxication Mimicking Acute Stroke. Clin Pract Cases Emerg Med.; 2(2): 155-157.

Macfarlane, M.; Shahab, J.; Willis, D. and Macfarlane, M. (2020): Clozapine toxicity: a cautionary palliative care tale BMJ Supportive \& Palliative Care;0:1-2.

McGrath, J.L. and Bachmann, D.J. (2018): "Vital Signs measurements". In: Roberts and 
Hedges 'Clinical Procedures in Emergency Medicine E-Book Roberts JR, Hedges JR (eds),7th ed., Elsevier Health Sciences:1-24.

\section{Midbari Y; Ebert T; Kosov I; Kotler} $M$; Weizman $A$ and $\operatorname{Ram} A$ (October 2013): "Hematological and cardiometabolic safety of clozapine in the treatment of very early onset schizophrenia: a retrospective chart review". Journal of Child and Adolescent Psycho pharmacology ; 23 (8): 516-21.

Numata, S.; Umehara, H. ; Ohmori, T. and Hashimoto, R. (2018): Clozapine Pharmacogenetic Studies in Schizophrenia: Efficacy and Agranulocytosis. Front Pharmacology.; 9: 1049.

Postema, P.G. and Wilde, A.A. (2014): "The measurement of the QT interval". Current Cardiology Review; 10(3):287-294.

Robinson, D.S. (2007):"CNS Receptor Partial Agonists: A New Approach to Drug Discovery". Primary Psychiatry;

14 (8): 22-24.

Song, M.K. ; Bahk, W.M. ;Kwon, Y. J. ; Yoon, B.H. and Lee,
S.Y.(2018): A Case of leukocytosis associated with clozapine treatment for the management of chronic Schizophrenia. Schizophrenia Bulletin; 44(1): S218-S219.

Taylor, D. L.; Tiwari, A. K.; Lieberman, J. A.; Potkin, S. G.; Meltzer, H. Y. and Knight J. (2017): Pharmacogenetic analysis of functional glutamate system gene variants and clinical response to clozapine. Mol Neuropsychiatry; 2:185-197.

Warnez, S. and Alessi-Severini, S. (2014): Clozapine: a review of clinical practice guidelines and prescribing trends. BMC Psychiatry ;14:102.

West, S; Jeffery-Smith, A. and Brownlee, W. (2013): Covert clozapine overdose: clozapine toxicity in a naive patient. Aust $\mathrm{N} \mathrm{Z}$ J Psychiatry;47(12):1208-9

Wu, Y.; Blichowski, M. ;Daskalakis, Z.J.; Wu, Z.; Liu, C.C. and Cortez, M.A. (2011): "Evidence that clozapine directly interacts on the GABAB receptor". Neuro Report; 22(13): 637-41. 


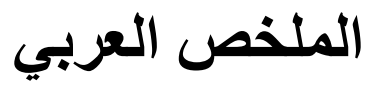

\author{
خصائص و مصير مرضى التسمم الحاد بعقار الكلوزابين مع مراعاة خاصة لمظاهره القبية

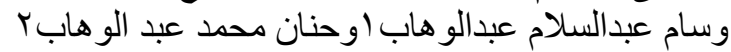

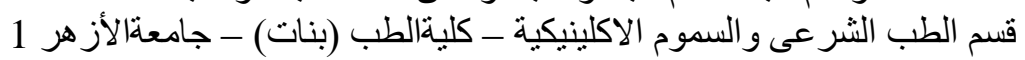 \\ مركز علاج التسمم - مستشفيات جامعة الاكينشمس 2
}

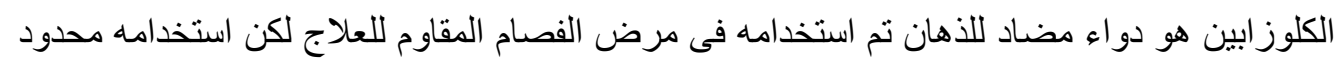

مقدمة:

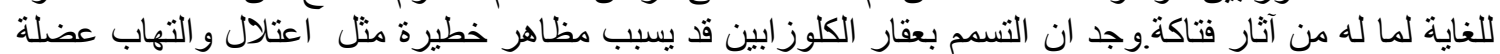

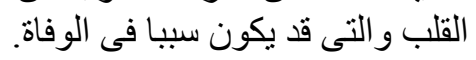

كان الهدف من هذا البحث دراسة الخصائص والنتايج لحالات تسمم الكلوزابين الحاد مع مر اعاة

الهـف:

خاصة لمظاهره القلبيه. اليف.

المرضى وطريقة البحث:

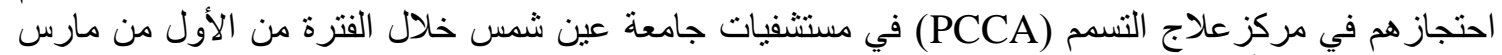

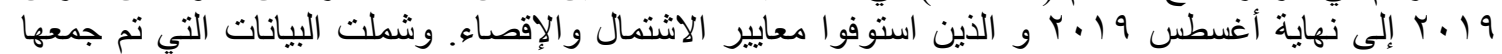

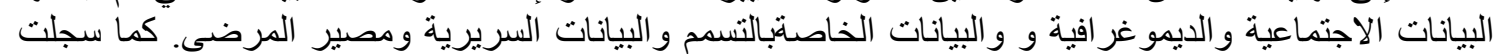
أيضا المظاهر القلبية. تم إجر اء تحليلات روتئية والينية لكل مريض تشنتمل على تسجيلات رسم القلب.

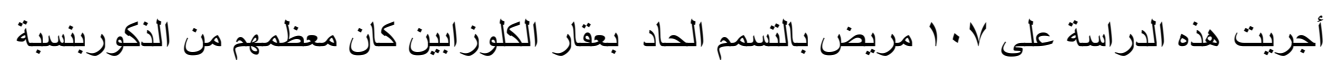

النتائج:

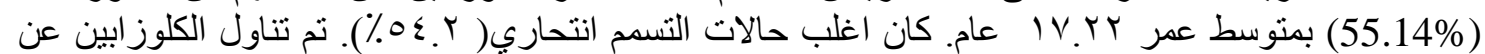

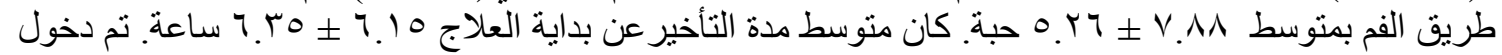

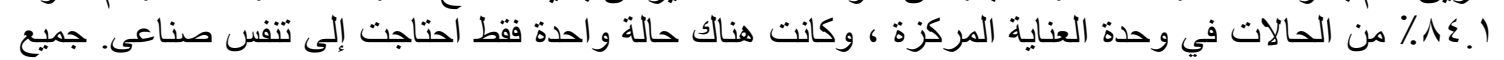

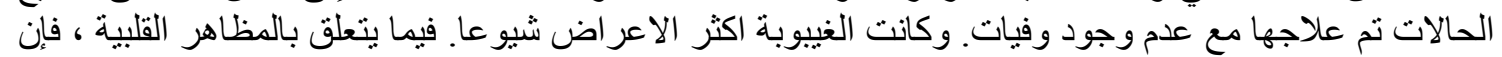

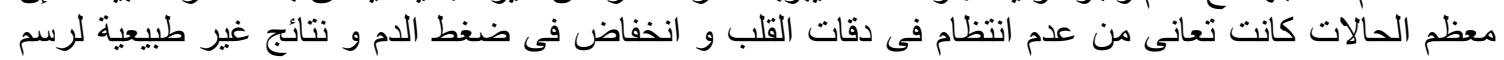

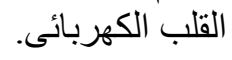

الخلاصة:

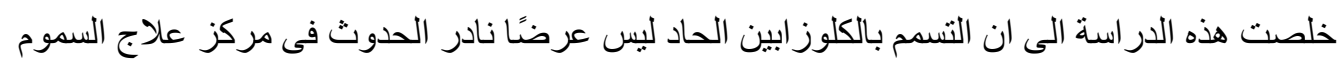

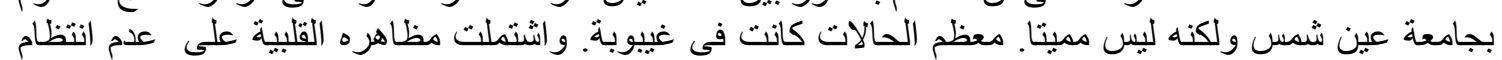

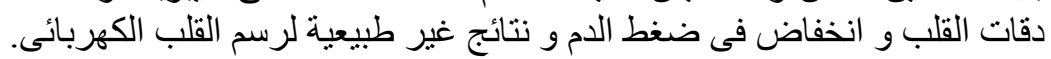

